\title{
ESTIMATION OF EMPENNAGE DESIGN WEIGHT IN CONCEPTUAL DESIGN PHASE FOR TACTICAL UAVs
}

\author{
Abdulhakim Muhammad Essari \\ Department of Mechanical and Industrial Engineering, Elmergib University, Alkhoms - Libya \\ DOI: https://doi.org/10.21467/proceedings.4.35 \\ * Corresponding author email: hakimsari@yahoo.com
}

\begin{abstract}
New formulas for empennage weight estimation and for takeoff weight estimation, in conceptual design phase are derived for a tactical unmanned aerial vehicle (TUAV). Formulas are derived by analyzing existing UAVs of the weighs from 100 to $500 \mathrm{~kg}$, and which have similar characteristics. Based on statistical trends, obtained from analyzed existing UAVs, takeoff weight is estimated from mission specification, and given payload weight. Software tools are developed in Matlab to facilitate takeoff and component weight calculations. The least square method is applied to analyze statistical data in order to develop trend functions which correlate TUAVs empty weight and takeoff weight. Existing formulas, developed for general aviation, for empennage and takeoff weight estimations are applied to TUAV and promising one are selected and adjusted to TUAV conceptual design phase. Empennage weight is related to geometrical parameters, maximum speed, and takeoff weight of the TUAVs
\end{abstract}

KEYWORDS: TUAV, Empennage, takeoff weight, conceptual design phase.

\section{Introduction}

The dependence on Unmanned Aerial Vehicles (UAV's) in last decade grow significantly especially for combat missions, and the demand for UAV's is greatly increased. UAV's play an important role in fields like, information superiority, collateral damage, urban area fighting and precision strikes against high payoff targets. UAV's evolved to include size growth of strategic UAV's for carrying more payload weight, and longtime endurance, and minimize tactical UAV's size. The most important parameter which dictates all other design parameter is estimation of the UAV's weight. Since there are no enough reliable sources for such estimation, the main goal of this paper is to establish empirical relationships which will lead to reliable empennage weight estimation of the UAV's, with emphasis on tactical UAV's. Only (C) 2018 Copyright held by the author(s). Published by AIJR Publisher in Proceedings of First Conference for Engineering

Sciences and Technology (CEST-2018), September 25-27, 2018, vol. 2 .
This is an open access article under Creative Commons Attribution-NonCommercial 4.0 International (CC BY-NC 4.0) This is an open access article under Creative Commons Attribution-NonCommercial 4.0 International (CC BY-NC 4.0)
license, which permits any non-commercial use, distribution, adaptation, and reproduction in any medium, as long as the
original work is properly cited. ISBN: $978-81-936820-6-7$ 
conceptual design phase is considered to be effort of relatively small group of engineers and specialists. This phase is also the cheapest it should provide the answer if the vehicle is possible to design and what characteristics will it have. It is also only paper phase requiring no special equipment and research. Outer geometry of the vehicle is also defined in this phase.[1] Since conceptual design phase cost least, it is wise to perform it thoroughly and to postpone crucial decisions as late as possible since all subsequent phases are continuation of this phase. This research will contribute to this problem by deriving equations for empennage weight estimation.

\section{Materials and Methods}

Models of conventional tactical UAVs weights between 100 to $450 \mathrm{kgs}$ are chosen for empennage weight estimation. [2] The parameters values of these UAVs are input into Matlab program to get the results on charts, the results are evaluated for UAV weights $220 \mathrm{~kg}$ as takeoff weight to find out the suitable empennage weight.

\subsection{Jay Gundlach Method: [1]}

The formula used by Gundlach is established for both small and big aircrafts by changing $w_{a}$ value according to the aircraft type. $\mathrm{W}_{\mathrm{a}}$ ranges between $3.5-8 \mathrm{lb} / \mathrm{ft} 2$ for supersonic fighters and between $0.8-1.2$ for small aircrafts. As shown in figure (1).

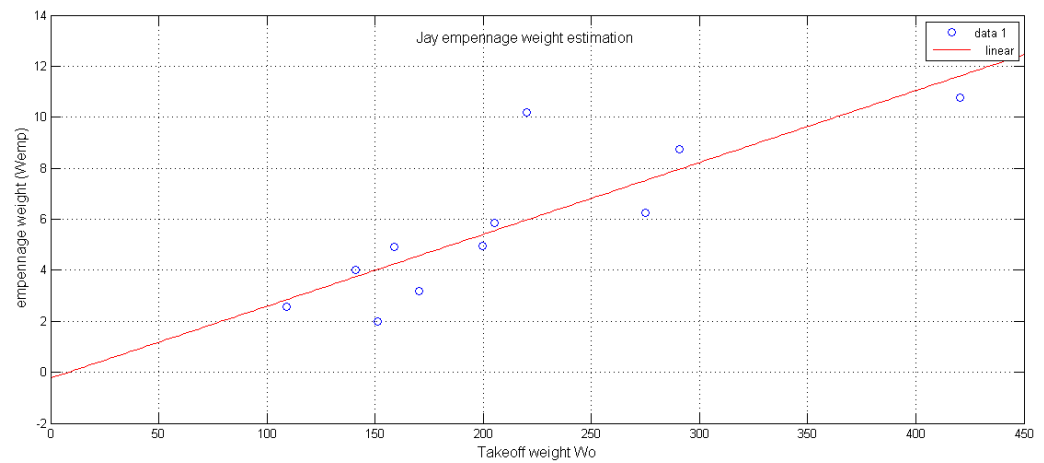

Figure (1) Jay Gundlach empennage weight estimation

$$
, \quad w_{a}=0.8: 1.2 \mathrm{lb} / \mathrm{ft} 2 \mathrm{Wemp}=w_{a} \times\left(S_{h}+S_{v}\right)
$$

$\mathrm{W}_{\mathrm{emp}}$, empennage weight, $\mathrm{S}_{\mathrm{H}}$ and $\mathrm{S}_{\mathrm{V}}$, surface areas of horizontal and vertical stabilizer.

\subsection{Usaf Method: [3]}

The equations suggested by United States air force (Usaf) for finding empennage weight estimation should be applied to aircrafts with performance doesn't exceed 300 knots speed.

Proceedings of First Conference for Engineering Sciences and Technology (CEST-2018), vol. 2 


\subsubsection{Horizontal Tail:}

$$
W_{h}=127 \times\left(\left(\frac{w_{o} N_{z}}{10^{5}}\right)^{0.87} \times\left(\frac{S_{h}}{100}\right)^{1.2} \times 0.289 \times\left(\frac{l_{h}}{10}\right)^{0.483} \times\left(\frac{b_{h}}{t_{h}}\right)^{0.5}\right)^{0.458}
$$

Where, $\mathrm{W}_{\mathrm{o}}$, takeoff weight of $\mathrm{UAV}, \mathrm{S}_{\mathrm{H}}$ and $\mathrm{S}_{\mathrm{V}}$, surface areas of horizontal and vertical stabilizer, $\mathrm{L}_{\mathrm{H}}$ and $\mathrm{LV}_{\mathrm{V}}$, horizontal and vertical stabilizer arm (distance between center of gravity and aerodynamic center), $b$, the wing span, $t$, tail thickness, $\mathrm{N}_{\mathrm{z}}$, ultimate load factor,

Figure (2) explain the relationship between takeoff weight and horizontal tail weight

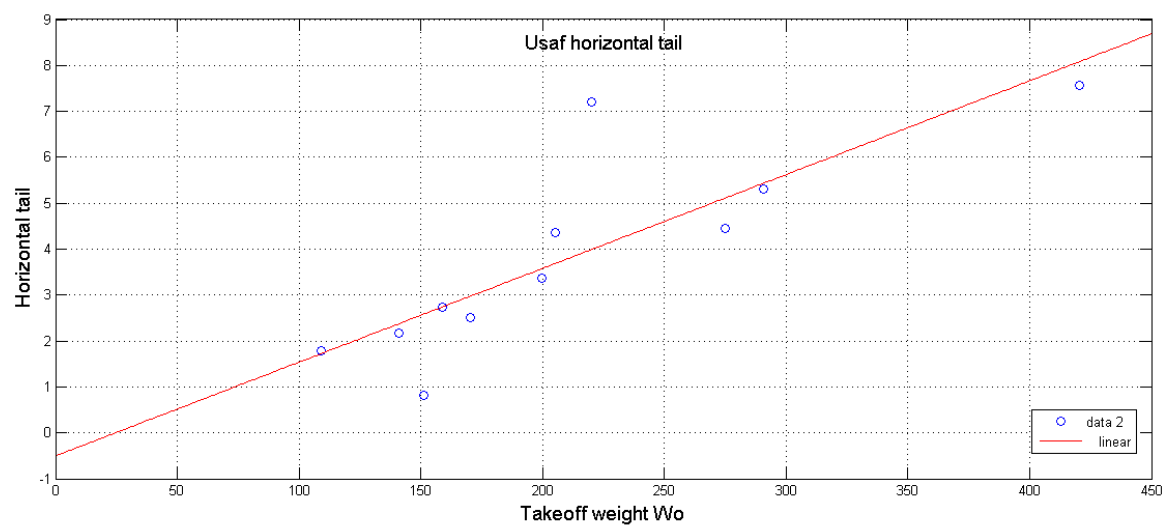

Figure (2) Usaf horizontal tail weight estimation

\subsubsection{Vertical Tail:}

$$
W_{v}=98.5 \times\left(\left(\frac{w_{o} N_{z}}{10^{5}}\right)^{0.87} \times\left(\frac{S_{v}}{100}\right)^{1.2} \times 0.289 \times\left(\frac{b_{v}}{t_{v}}\right)^{0.5}\right)^{0.458}
$$

By substitution in equation (3) for V-tail weight estimation we get the results shown in figure (3), figure (4) show the results got for equation (4).

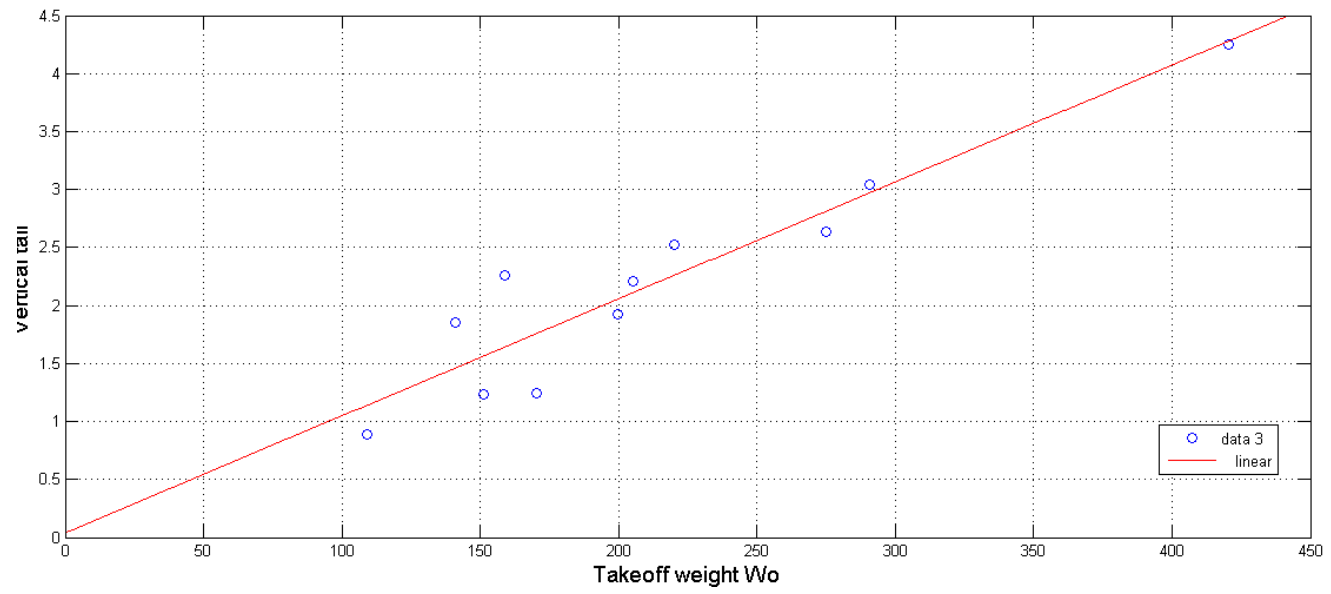

Figure (3) Usaf vertical tail weight estimation 
Abdulhakim Muhammad Essari, CEST-2018, AIJR Proceedings 4, pp.675-685, 2018

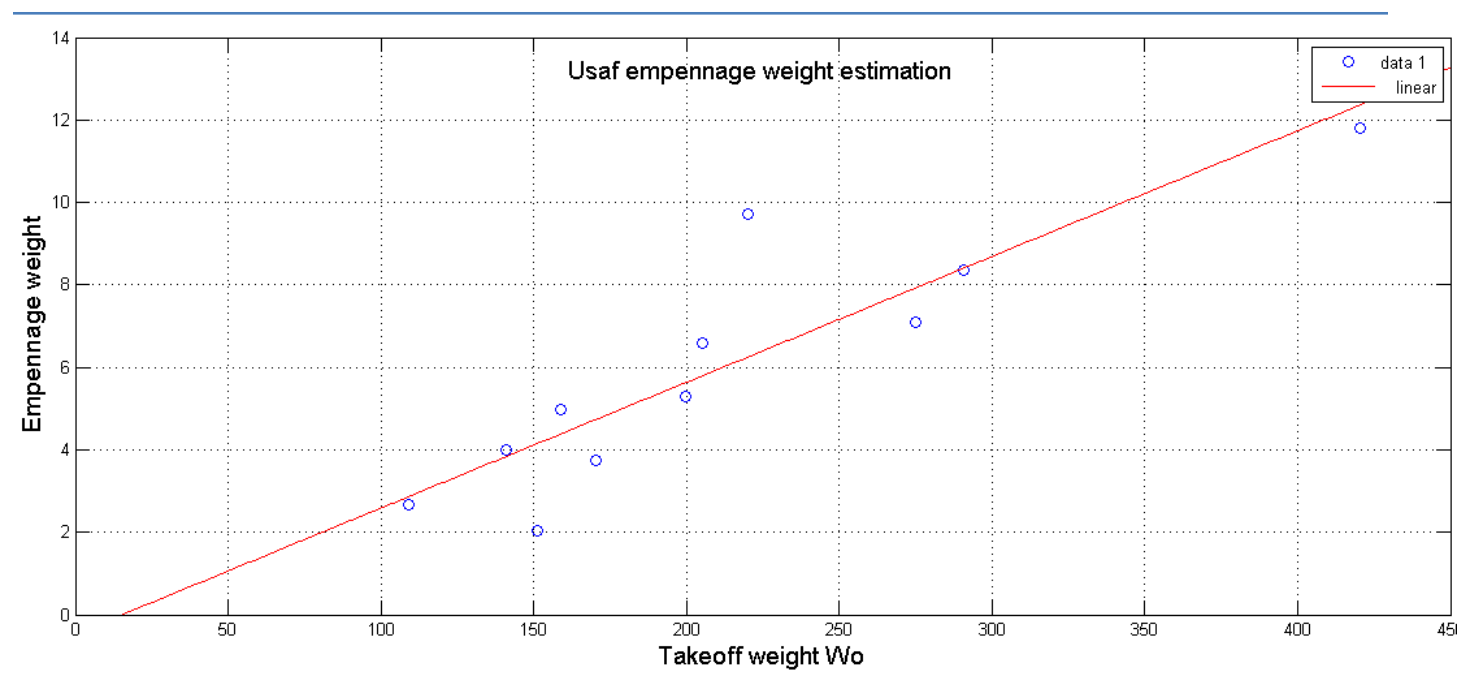

Figure (4) Usaf empennage weight estimation

\subsection{Torenbeek Method: [4]}

The following equation is applied to light transport aircrafts which has dive speed less than 200 knots.

$$
W_{\text {emp }}=0.04 \times\left(N_{z} \times\left(S_{v}+S_{h}\right)^{2}\right)^{0.75}
$$

Where, $W_{e m p}$ is empennage weight. $S_{H}$ and $S_{V}$ are surface areas of horizontal and vertical stabilizer, and $\mathrm{Nz}$ is ultimate load factor.

Torenbeek equation (4), is a simple equation and it is completely depends upon the areas of both horizontal and vertical tails and ultimate load factor.

By substitution in Torenbeek equation (4) we get the results shown in figure (5):

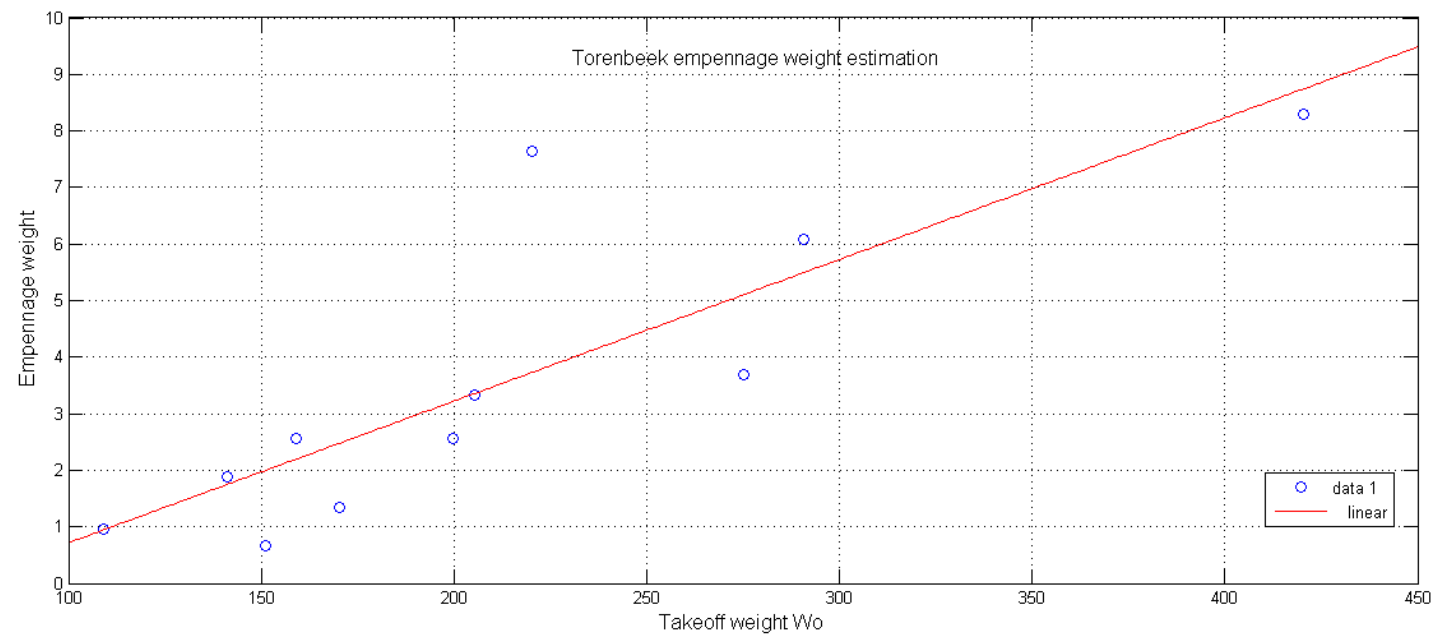

Figure (5) Torenbeek empennage weight estimation

Proceedings of First Conference for Engineering Sciences and Technology (CEST-2018), vol. 2 678 


\subsection{Raymer Method: [3]}

The following equations from Raymer are established for general aviation aircrafts.

\subsubsection{Horizontal Tail:}

Raymer equation for horizontal tail weight estimation is:

$$
\begin{aligned}
W_{h}=0.016 \times & \left(N_{z} \times W_{d g}\right)^{0.414} \times q^{0.168} \times S_{h}^{0.896} \times\left(\frac{100 \times t / c}{\cos \Lambda}\right)^{-0.12} \\
& \times\left(\frac{A}{\cos ^{2} \Lambda_{h}}\right)^{0.043} \times \lambda_{h}^{-0.02}
\end{aligned}
$$

Where, $\mathrm{S}_{\mathrm{H}}$ and $\mathrm{S}_{\mathrm{V}}$, surface areas of horizontal and vertical stabilizer, b, the wing span, C is mean aerodynamic chord, $\mathrm{V}_{\mathrm{H}}$, Tail volume coefficient, $\mathrm{V}_{\mathrm{V}}$, Vertical Tail volume coefficient, $\mathrm{t}$, tail thickness, $\mathrm{N}_{z}$, ultimate load factor, $\mathrm{A}$, aspect ratio, $\mathrm{q}$, dynamic pressure, $\Lambda$, sweep angle at $25 \%$ MAC, $\lambda$, taper ratio.

Figure (6) show the relationship between takeoff weight and horizontal tail weight according to equation (5).

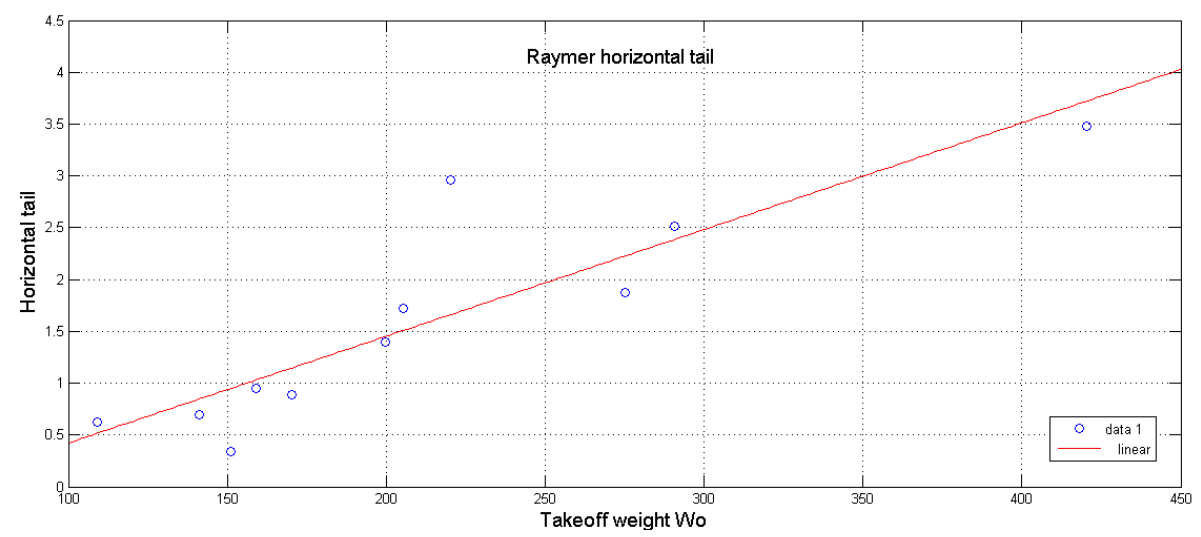

Figure (6) Raymer horizontal tail weight estimation

\subsubsection{Vertical Tail:}

$$
\begin{aligned}
W_{h}=0.073 \times & \left(1+0.2 \times \frac{H_{t}}{H_{v}}\right) \times\left(N_{z} \times W_{d g}\right)^{0.376} \times q^{0.122} \times S_{h}^{0.873} \\
& \times\left(\frac{100 \times t / c}{\cos \Lambda}\right)^{-0.49} \times\left(\frac{A}{\cos ^{2} \Lambda_{h}}\right)^{0.357} \times \lambda_{h}^{0.039}
\end{aligned}
$$

From equation (6) we got the results shown in figure (7), 
Abdulhakim Muhammad Essari, CEST-2018, AIJR Proceedings 4, pp.675-685, 2018

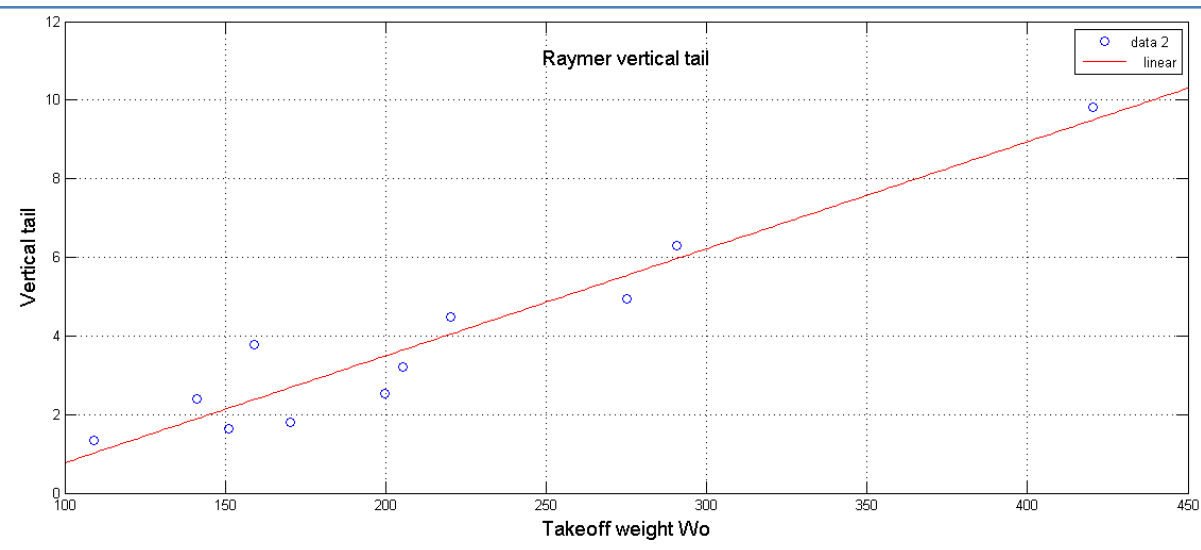

Figure (7) Raymer vertical tail weight estimation

Figure (8) explain the results for empennage group, (horizontal and vertical), weight estimation from Raymer.

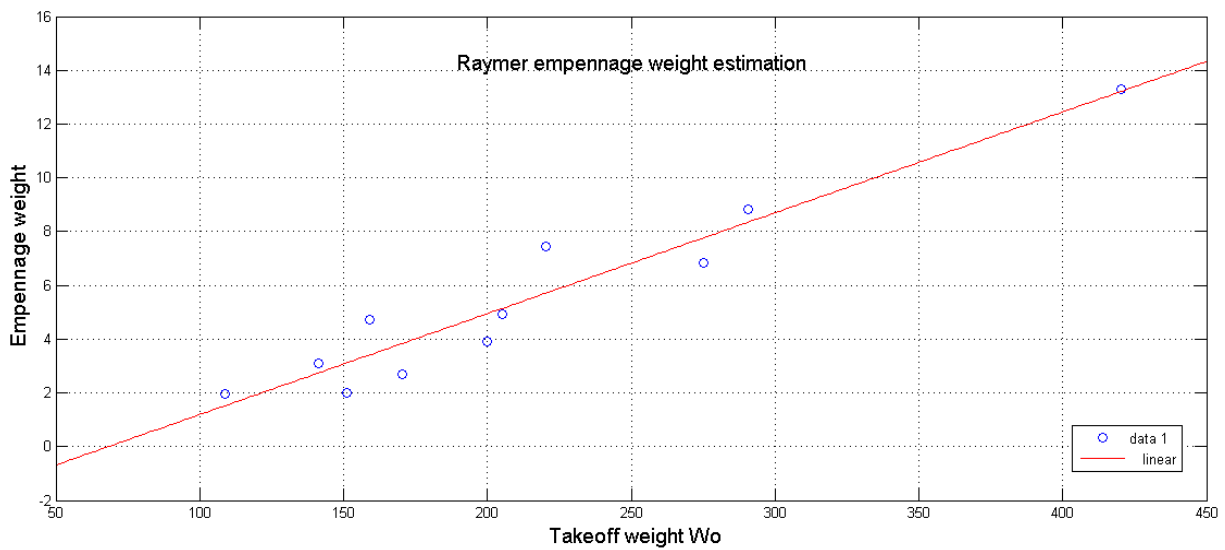

Figure (8) Raymer empennage weight estimation

\subsection{Kundu Method: [5]}

Horizontal and vertical tails are lifting surfaces. The empennage does not have an engine or undercarriage installation.

Both the horizontal and vertical tails plane mass estimations have a similar form but they differ in the values of constants used.

The equation used here is established for Civil Aircraft.

$$
M_{\text {emp }}=0.0213 \times\left(M_{t o} \times N_{z}\right)^{0.48} \times S_{w}^{0.78} \times A \times(1+\lambda)^{0.4} /\left(\cos \Lambda \times t / c^{0.4}\right)
$$

$M_{e m p}$ - empennage mass, $M_{t o}$ - takeoff weight mass

For nonmetals are used, if there is reduction in mass due to lighter material, then the mass is reduced by that factor. If there is a $10 \%$ mass saving, then:

$M_{E}$ nonmetal $=0.9 \times M_{E}$ all metal 
Figure (9) show the results got from equations (7) and (8) for empennage weight estimation.

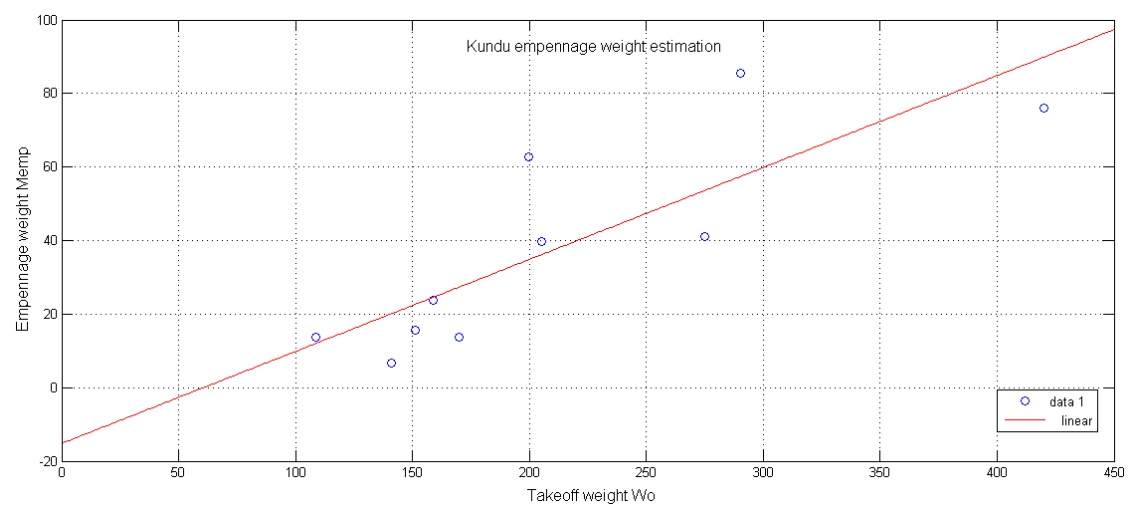

Figure (9) Kundu empennage weight estimation

\subsubsection{Horizontal Tail:}

$$
\begin{gathered}
M_{H}=0.02 \times k \operatorname{conf} \times\left(M_{t o} \times N_{z}\right)^{0.48} \times S_{w}^{0.78} \times A \times(1+\lambda)^{0.4} / \\
\left(\cos \Lambda \times t / c^{0.4}\right)
\end{gathered}
$$

\subsubsection{Vertical Tail:}

$$
\begin{aligned}
M_{v}=0.0215 \times k \operatorname{conf} \times & \left(M_{t o} \times N_{z}\right)^{0.48} \times S_{w}^{0.78} \times A \times(1+\lambda)^{0.4} / \\
& \left(\cos \Lambda \times t / c^{0.4}\right)
\end{aligned}
$$

For V-tail configurations, use $k_{\text {conf }}=1.1$ for a T-tail, 1.05 for a midtail, and 1.0 for a low tail.

Where, $\mathrm{W}_{\mathrm{o}}$, takeoff weight of $\mathrm{UAV}, \mathrm{W}_{\mathrm{emp}}$, empennage weight, $\mathrm{S}_{\mathrm{H}}$ and $\mathrm{S}_{\mathrm{V}}$, surface areas of horizontal and vertical stabilizer, $\mathrm{S}$, wing reference area, $\mathrm{L}_{\mathrm{H}}$ and $\mathrm{LV}_{\mathrm{V}}$, horizontal and vertical stabilizer arm (distance between center of gravity and aerodynamic center), b, the wing span, $\mathrm{C}$ is mean aerodynamic chord, $\mathrm{V}_{\mathrm{H}}$, Tail volume coefficient, $\mathrm{V}_{\mathrm{V}}$, Vertical Tail volume coefficient, t, tail thickness, $\mathrm{N}_{z}$, ultimate load factor, $\mathrm{A}$, aspect ratio, $\mathrm{q}$, dynamic pressure, $\Lambda$, sweep angle at $25 \% \mathrm{MAC}, \lambda$, taper ratio.

\subsection{Kroo Method: [6]}

Kroo introduces two formulas for both horizontal and vertical tails.

\subsubsection{Horizontal Tail:}

The horizontal tail weight, including elevator, is determined similarly, but the weight index introduces both exposed and gross horizontal tail areas as well as the tail length (distance from airplane c.g. to aerodynamic center of the horizontal tail). The method assumes that the elevator is about $25 \%$ of the horizontal tail area.

$$
W_{h}=5.25 \times S_{h}+0.8 \times 10^{-6} \times \frac{\left(N_{z} \times b_{h}{ }^{3} \times W_{o} \times \operatorname{mac} \times S_{h}^{0.5}\right)}{\left(\left(\frac{t_{h}}{c_{h}}\right) \times(\cos )^{2} y_{h} \times l_{h} \times S_{h}^{1.5}\right)}
$$


Figures (10),(11), and (12) explain the results of equations (10) and (11) for horizontal, vertical, and empennage weight estimation by Kroo method.

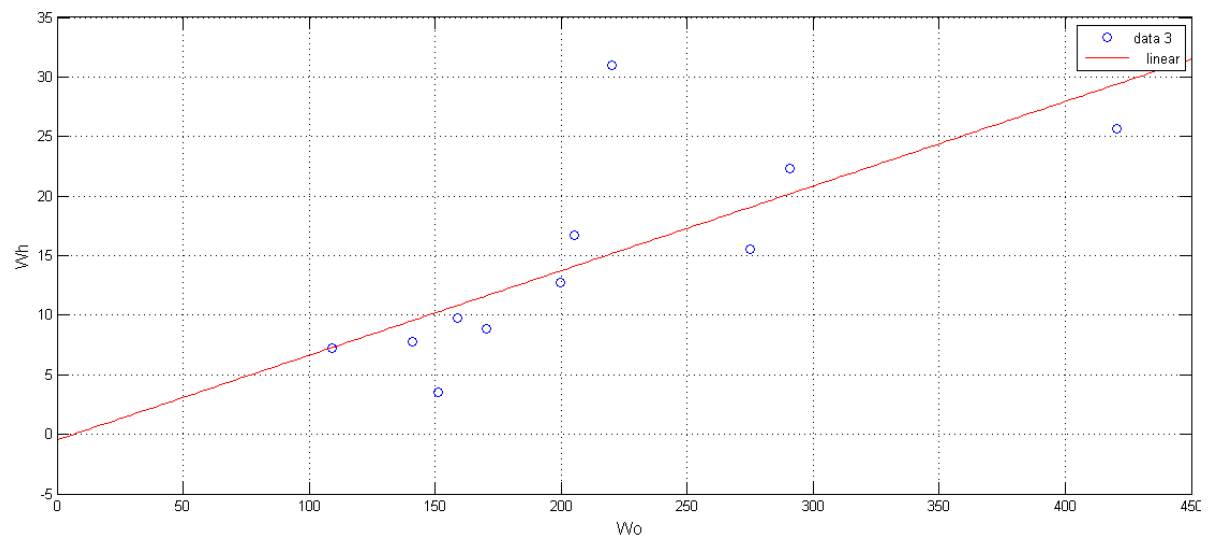

Figure (10) Kroo horizontal tail weight estimation

\subsubsection{Vertical Tail:}

The rudder itself may be assumed to occupy about $25 \%$ of $S_{\mathrm{V}}$ and weighs $60 \%$ more per area.

The weight of the vertical portion of a T-tail is about $25 \%$ greater than that of a conventional tail; a penalty of $5 \%$ to $35 \%$ is assessed for vertical tails with center engines.

$$
W_{V}=2.62 \times S_{v}+15 \times 10^{-6} \times \frac{\left(N_{z} \times b_{v}{ }^{3}\left(0.8+0.44 \times\left(W_{o} / S_{r e f}\right)\right)\right)}{\left(\left(\frac{t_{h}}{c_{h}}\right) \times\left(\cos y_{h}\right)^{2}\right)}
$$

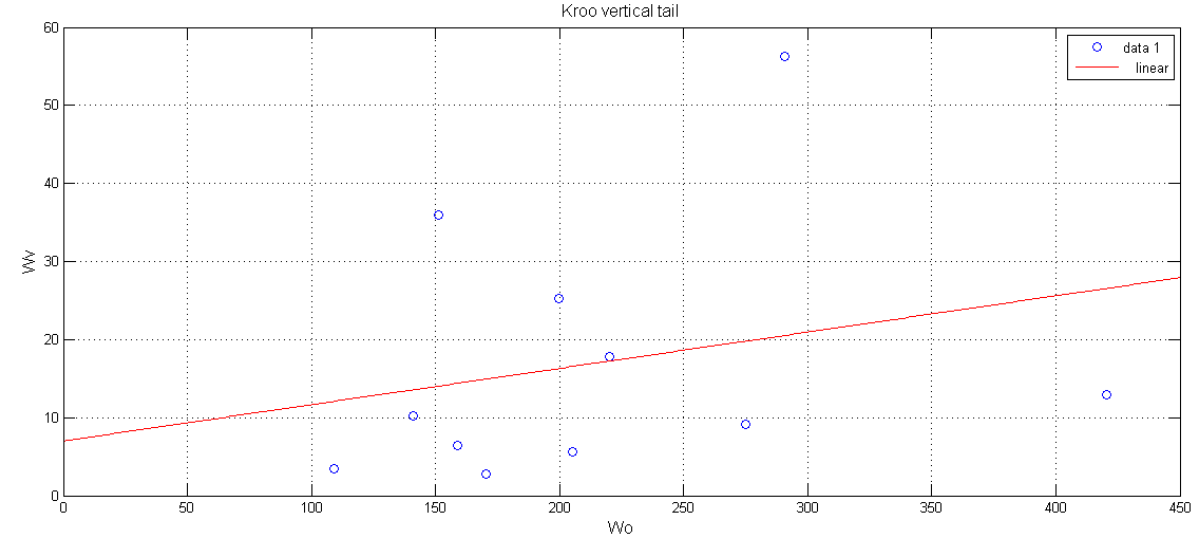

Figure (11) Kroo vertical tail weight estimation 


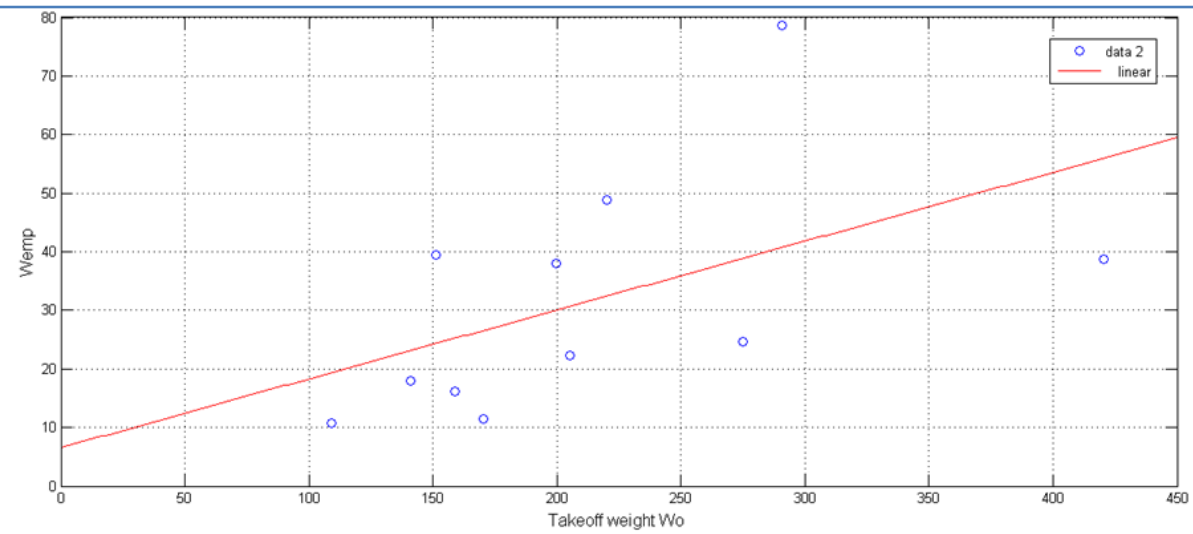

Figure (12) Kroo empennage weight estimation

3 Results and Discussion:

\subsection{Empennage Weight Formulas Selection:}

For empennage weight estimation many formulas were used for finding the estimated empennage weight, and the results were explained on charts to get the best one. The formulas used for empennage weight mostly were founded for general aviation aircrafts and because of presence a lot of tail group shapes and designs. So in some cases we see unreasonable and extreme results for empennage weight estimation, but in some few cases we got acceptable results such as in Jay Gundlach, Torenbeek and Usaf formulas.

Empennage group has no specific design criteria, because some UAVs have special empennage shapes, some of them have no horizontal tail instead they have delta wing, in some cases the vertical tail is much bigger than the horizontal tail and in some case there are two vertical tails.

\subsection{New Formula for Empennage Weight Estimation:}

These equations of our work for horizontal and vertical tails weight estimation are modified of Cessna equations. They should be applied to small size and low performance aircrafts which has maximum speed less than $350 \mathrm{~km} / \mathrm{hr}$. [7], [8].

\subsubsection{Horizontal Tail:}

The equation from Cessna for horizontal tail weight estimation, originally established for general aviation aircrafts. The new equation (12) now is valid for UAV's.

$$
W_{h}=\frac{1.46 \times(W o)^{0.887} \times\left(S_{h}\right)^{0.101} \times A_{h}^{0.138}}{57.5 \times t_{r}^{0.223}} l b
$$

Where, $\mathrm{W}_{\mathrm{o}}$ is takeoff weight, $\mathrm{S}_{\mathrm{H}}$ and $\mathrm{S}_{\mathrm{V}}$, surface areas of horizontal and vertical stabilizer, $\mathrm{b}$, the wing span, $\mathrm{C}$ is mean aerodynamic chord, $\mathrm{V}_{\mathrm{H}}$, Tail volume coefficient, $\mathrm{V}_{\mathrm{V}}$, Vertical Tail 
volume coefficient, $t$, tail thickness, $\mathrm{N}_{z}$, ultimate load factor, $\mathrm{A}$, aspect ratio, $\mathrm{q}$, dynamic pressure, $\Lambda$, sweep angle at $25 \% \mathrm{MAC}, \lambda$, taper ratio.

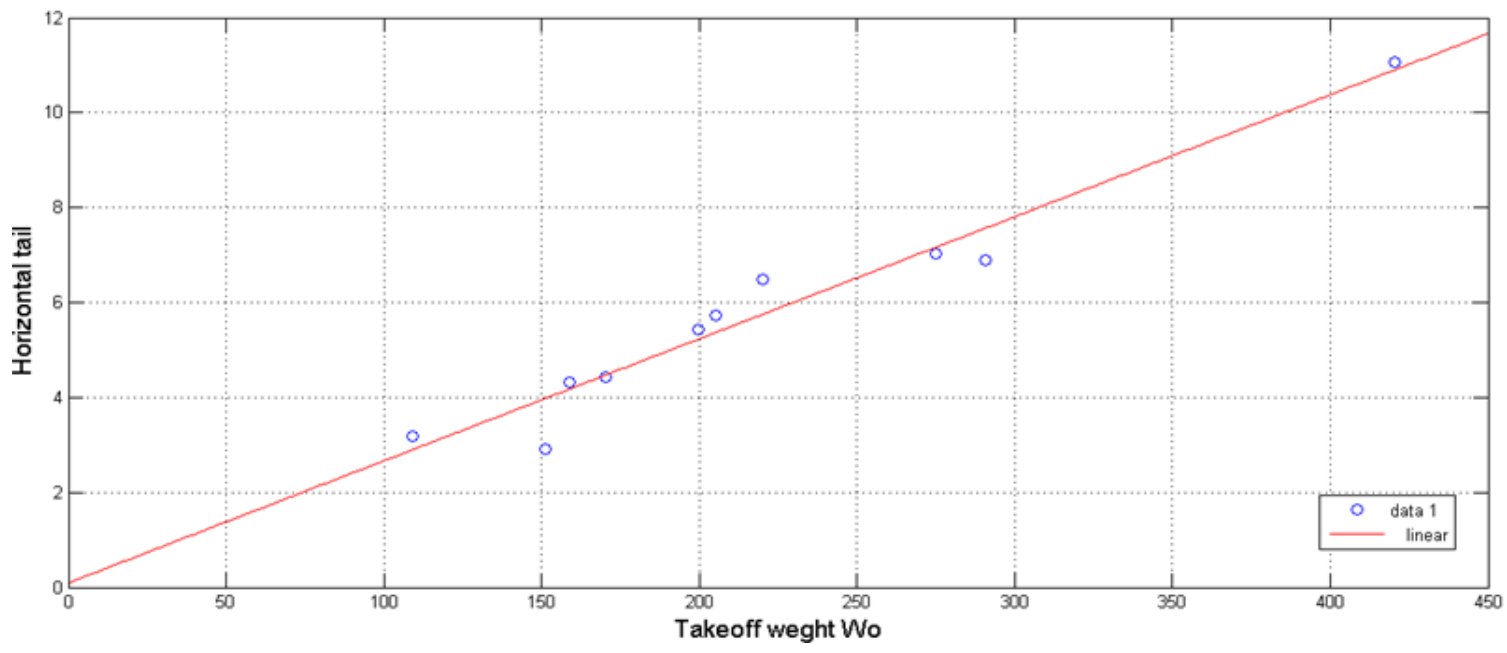

Figure (13) chart for the new equation for horizontal tail weight estimation

\subsubsection{Vertical Tail:}

The equation from Cessna for vertical tail weight estimation, originally established for general aviation aircrafts. My equation (13) now is valid for UAV's.

$$
W_{v}=\frac{0.039 \times W_{o}^{0.567} \times S_{v}^{1.249} \times A_{v}^{0.482}}{15.6 \times t_{r}^{0.747} \times\left(\cos \Lambda_{1 / 4}\right)^{0.882}} l b
$$

Figure (14) show the results from equation (13) for vertical tail weight estimation by the new equation.

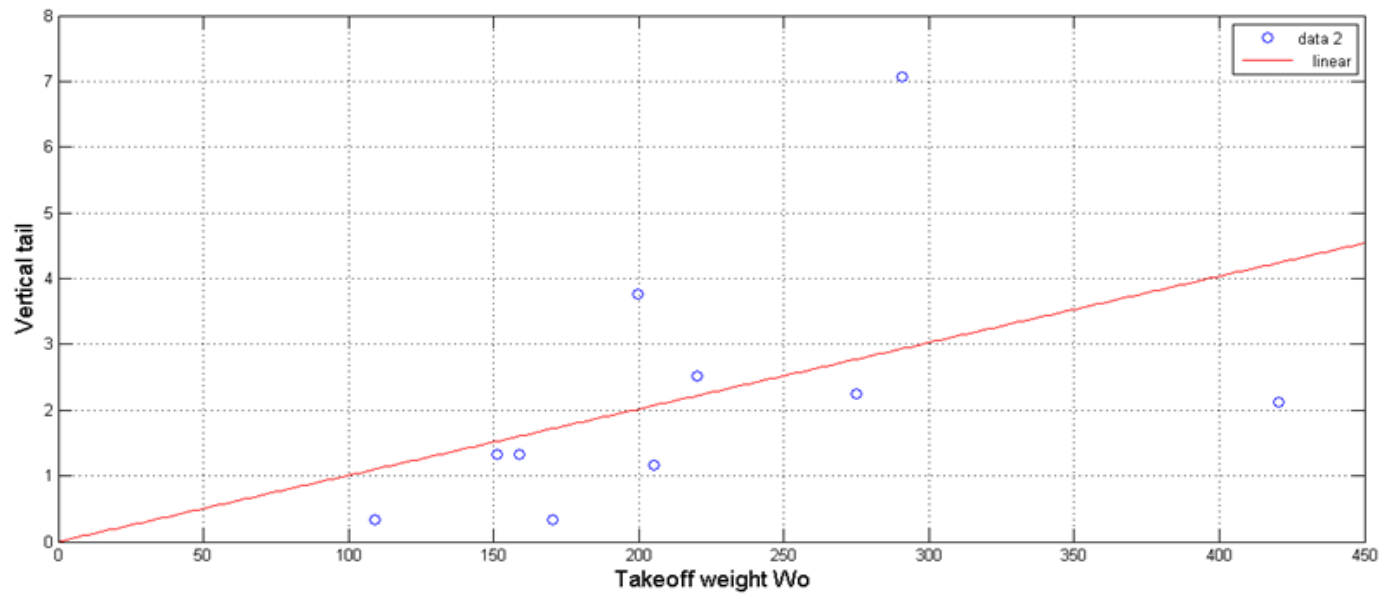

Figure (14) chart for the new equation for vertical tail weight estimation 


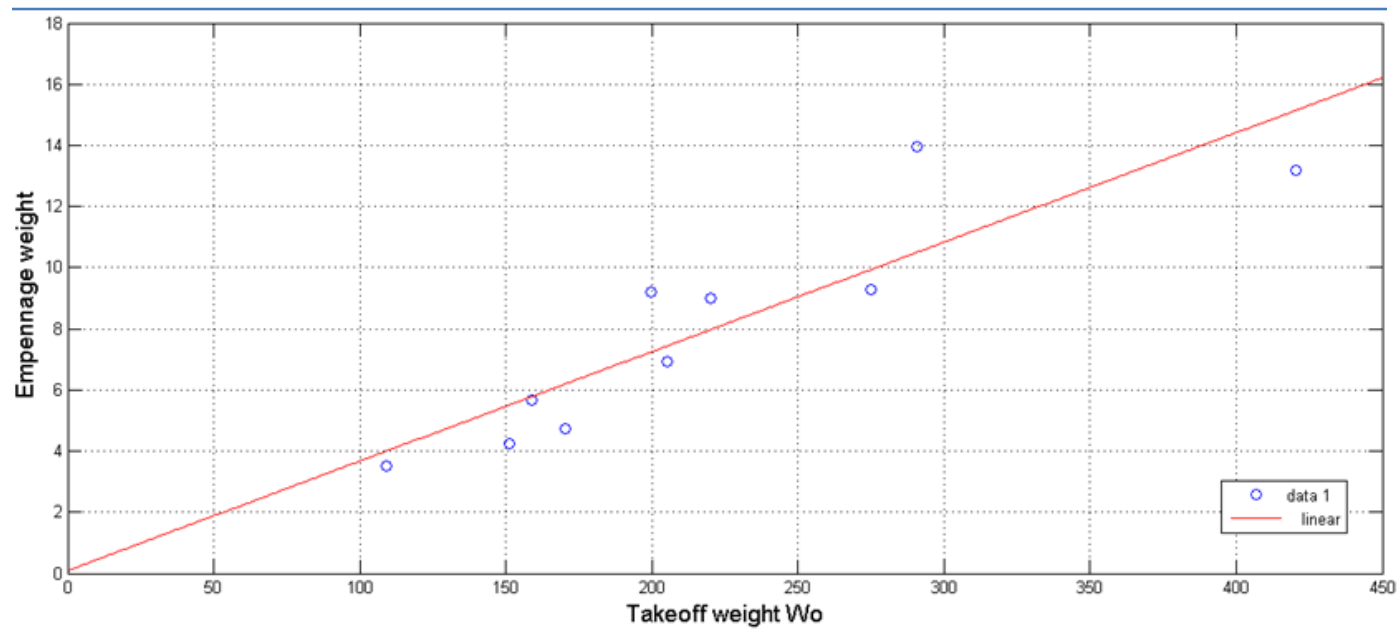

Figure (15) Empennage group

\section{Conclusions}

Various weight design formulas are applied to estimate empennage weights of UAVs. Since these formulas are developed for manned aircrafts (which are much heavier than tactical UAVs) they sometimes give unacceptable estimations (to high values or to small values than it could be expected by common sense). Modification in coefficients of the available formulas is done in order to get better fit UAV design process. These modified formulas are the main contribution of this paper. Application of these formulas estimates more accurately empennage weight of the UAVs. Two suggested formulas for empennage weight estimation including horizontal and vertical tails are introduced.

\section{References:}

[1] Jay Gundlach. Designing Unmanned Aircraft Systems: A Comprehensive Approach. Published by the American Institute of Aeronautics and Astronautics, Inc. 2012.

[2] Paul Jackson. Jane's All the World's Aircraft. 2004-2005.

[3] Daniel P. Raymer. Aircraft Design: A conceptual Approach. Published by the American Institute of Aeronautics and Astronautics, Inc. Second Edition 1992.

[4] Egbert Torenbeek. Synthesis of subsonic airplane design. Torenbeek1976

[5] Ajoy Kumar Kundu. Aircraft Design. Published in the United States of America by Cambridge University Press, New York. 2010.

[6] Ilan Kroo. Aircraft Design: Synthesis and Analysis. This textbook is copyright by Desktop Aeronautics, Inc. 2001.

[7] Jan Roskam. Aircraft Design. Part 5. Component Weight Estimation. 1989.

[8] Mohammad H. Sadraey. Aircraft Design: A system Engineering Approach. A john Wiley \& Sons, Ltd Publications. 2012. 